\title{
Perceptions and Anxiety Level of Eight Grade Students Engaged in Guided Inquiry Physics Experiment
}

\author{
L D Oraa $^{1}$ and V M Mistades ${ }^{2}$ \\ \{voltaire.mistades@dlsu.edu.ph\} \\ Bina Bangsa School - Semarang, Indonesia ${ }^{1}$ \\ De La Salle University, Manila ${ }^{2}$
}

\begin{abstract}
Research on inquiry-based laboratory experiments have shown its effectivity in developing student's science process skills, critical thinking, problem solving ability, and understanding of the nature of science. In the Philippines, however, information regarding the performance of high school learners doing a guided inquiry Physics experiment (GIPE) is limited. Using a mixed-method approach, the study looked into the perceptions and anxiety level of Grade 8 learners while engaged in a guided inquiry Physics experiment. An adapted scientific ability rubric was used to rate the level of laboratory performance of the students. Their performance was correlated with their anxiety level, which was measured using the Physics Laboratory Anxiety Assessment Scale. The over-all anxiety level of the students was rated as intermediate and there is no clear indication that their laboratory performance is correlated with their anxiety level. Data from the students' reflective journals and interviews were analyzed qualitatively to reveal categories that emerged from the content of the individual reflections. The following factors are relevant to the students' laboratory performance: working as a team, supportive behavior, science process skills, use of language, time constraint, and readiness to high level of inquiry.
\end{abstract}

Keywords: Perceptions, Anxiety, Guided Inquiry

\section{Introduction}

The goal of science education in the Philippines is to develop scientifically literate students and to prepare them to become informed and active citizens - capable of making judgements and decisions with regards to applications of scientific knowledge that may impact the society. To attain this end, the Department of Education has designed the K to 12 Science curriculum so that concepts and skills are presented with increasing complexity as the learners move from a grade level to the next, which is known as spiral progression. This is with the end in mind that the students will gain gradual mastery of science concepts and develop their science process skills which are essential for them to become critical problem solvers.

However, how can students improve their conceptual understanding and problem-solving skills when the typical classroom setting in the country is still teacher-centered and most of the time, the students are perceived and treated as passive learners [1] waiting like empty vessels to be filled with information by the teacher. In this light, it is important to acknowledge that learning is an active process. It is widely agreed that learning is maximized when students are engaged and involved in their own learning [2]. Experimental sciences such as physics require "hands-on" activities for its concepts to be grasped thoroughly; it is through laboratory 
experiments that the laws of physics are verified and confirmed. Alongside with the learning of the physics concepts, the primary goal of the laboratory is to provide an opportunity for the learners to carry out the processes of the scientific method as they conduct investigations and inquiry in order to improve their basic and integrated scientific process skills.

Although physics discussions are combined with a "hands-on component", the primary goal of the laboratory is being restricted because of the prevalent type of experiment being supplied to the students: confirmatory or "cookbook". Here, the step-by-step directions on how to arrive at the answer are specified; thus, sending a wrong signal to the students that there is only one formula of solving a science problem [3]. Also, with this setup, Rovira-Figueroa [4] remarked that students tend to focus more on completing the task in the laboratory experiment, while interpreting and presenting the results become secondary. This happens when students blindly follow the instructions given by the teacher or as specified in the laboratory manual. Consequently, the laboratory becomes a place where tasks set are being carried out instead of focusing on the methods and purposes during laboratory work.

Likewise, Hodson [5] asserts that the traditional "cookbook" format does not elicit critical thinking and higher order thinking skills, though he does not deny the fact that there is an explicit function for confirmatory experimentation, but he stresses the need for students to engage in designing at least a part of the investigation, if not the whole. The use of "science as inquiry" and inquiry-based laboratories have been the focal point of most researches because of its effectivity in developing the scientific process skills, critical thinking competence, problem solving ability and understanding of the nature of science among students [6]. A science laboratory program is moving towards more inquiry-based when greater elements are left for students to carry out.

Science inquiry refers to activities that imitate how scientists think and act [7]. It involves engaging learners in scientific practices such as asking scientific questions, experiencing phenomena by designing and conducting investigations, collecting and analyzing data, constructing explanations based on evidence, and sharing findings with others [8]. Arslan [9] formulated a representation to categorize laboratory activities called the Four-Level Model of Inquiry. The classification of a laboratory activity depends on how much the teacher supplies in the process of investigation. The first level is called the confirmation inquiry which is also known as the "cookbook type" of experimentation. Here, the students follow a prescribed procedure given by the teacher just the way how cookbooks are written; hence, the name given to it. Learners also know the answer to the inquiry before the activity starts. Second is the structured inquiry. In this level, the students are given the problem, as well as the detailed instruction on how to arrive at the answer; however, the students have no idea of the outcome, unlike in the confirmatory type of inquiry.

The third level is guided inquiry. The only component that the teacher will supply in this category is the question; the rest will be carried out by the students. This type of inquiry was utilized in this research paper. Finally, the highest level is known as the open inquiry. This is the most challenging for the students because they will go through the whole process of investigation all by themselves - from the formulation of questions to the conclusion. The teacher's sole function here is to give the area or field of research to study. This is somewhat giving the students the taste of how scientists work which is the essence of science inquiry.

This current research utilized inquiry-based laboratory; specifically, guided inquiry type of experimentation because of its potential to close the science process skills gap among learners. Although there were substantial number of published studies regarding inquiry-based laboratory, information regarding the performance of high school learners in doing higher level of inquiry Physics experiment is limited. For the purpose of extending the study in this area, this 
paper provided a snapshot of the laboratory performance, anxiety level, and perceptions of Grade 8 students in conducting a Guided Inquiry Physics Experiment (GIPE).

The purpose of this study was to determine the laboratory performance, anxiety level, and perceptions toward Guided Inquiry Physics Experiment (GIPE) of Grade 8 students from a National Trade School. In particular, it sought to answer the following questions. What is the laboratory performance level of the learners in a guided inquiry physics experiment as presented by the quality of their laboratory reports. What is the anxiety level of grade- 8 students on a guided inquiry Physics experiment. To what extent, if any, is there a relationship between the Grade 8 students' laboratory performance and anxiety level. What are the student's perceptions about a guided inquiry Physics experiment.

\section{Method}

\subsection{Research Design}

A mixed method research was employed for this study to gain a better understanding of the research field. Descriptive statistics was applied to report the laboratory performance and anxiety level of the research participants. Qualitative data was obtained from the students' reflective journal and interview to determine the respondents' perceptions about guided inquiry Physics experiment.

\subsection{Research Participants}

The respondents of this study consist of three (3) heterogeneous intact classes of Grade 8 students from a National Trade School. Each class is composed of roughly eighty-two (82) students. In the laboratory, the students were divided into groups of five to six students per group.

\subsection{Research Instruments}

\subsubsection{Laboratory Performance Rubric}

A scientific ability rubric developed by Etkina et al [10] was adapted with permission from the Rutgers Physics and Astronomy Education Research Group. This was used to rate the level of laboratory performance of the participants in delivering a GIPE by way of their laboratory reports. Principally, this was developed to assess the scientific abilities of the learners such as: (a) representing physical processes in multiple ways; (b) devising and testing a qualitative explanation or quantitative relationship; (c) modifying a qualitative explanation or quantitative relationship; (d) designing an experimental investigation; (e) collecting and analyzing data; (f) evaluating experimental predictions and outcomes, conceptual claims, problem solutions, and models, and ( $\mathrm{g}$ ) communicating the results of the experiment. For the present study, the researcher selected only the sets of rubrics in accordance to Rovira-Figueroa's [4] definition of an effective laboratory report.

\subsubsection{Physics Laboratory Anxiety Assessment Scale}

The anxiety that was brought about by the high-level physics experiment was explored using the adopted Physics Laboratory Anxiety Assessment Scale [11]. This instrument is 
composed of 16 items divided into four sub-dimensions, namely: (a) anxiety about finishing the experiment, (b) anxiety about doing the experiment as intended, (c) constant anxiety towards the physics laboratory, and (d) anxiety related to the use of materials in the laboratory. Three (3) items contained positive judgment while thirteen (13) items involved negative judgments.

\subsubsection{Reflective Journal Writing}

The research participants individually described his/her experience of the laboratory activity through reflective journal writing. After every laboratory activity, the students were asked to recount their thoughts, questions, and feelings about the activity. There are no guide questions, the learners are free to express themselves, which is vital for keeping a meaningful journal. Towndrow, Ling and Venthan [12] enumerated the benefits of Reflective Journal Writing: it may serve as an instructional and self-assessment tools, reflect the students' beliefs and attitudes toward science and about learning science, and it gives an opportunity for them to express their happiness, doubts and frustrations which make journals a rich source of information.

\section{Result and Discussion}

\subsection{Laboratory Performance Level of the Learners}

The learners were assigned to plan and conduct an investigation to determine the relationship between the mass of a material and the amount of heat that it can transfer. After performing the experiment, each group submitted their laboratory report containing the problem statement, hypothesis, experiment to test the hypothesis, data analysis, interpretation, and conclusion. Using the Laboratory Performance Rubric, the laboratory reports were assessed. Out of 45 groups, only $62 \%$ successfully submitted their output on time. Thirteen percent of the submitted manuscripts were found to be irrelevant to the topic. Some of these topics include: "Factors affecting the cooling rate of water", "Saturation of a solution", "How to separate salt from water", and "Soda explosion".

Characterizing the laboratory performance of the learners in the guided inquiry Physics experiment, almost $50 \%$ of the groups obtained a score of 3 (or were able to identify and state the problem to be solved clearly). However, more than $80 \%$ of the groups failed to design an experiment that tested the hypothesis. This high percentage affirms Harlen's [13] claim that designing an experiment is one of the most important and the most challenging part of the guided inquiry experiment. Despite the difficulty, there were eight (8) groups who were able to design an experiment that led to a conclusive judgement. It is interesting to note that they were able to come up with six (6) different set-ups that answers a single question.

Miller [14] advocates the view that when students were given an opportunity to explore a problem and formulate an answer to the problem on their own, creativity shines through. The results of this study support Miller's statement. In the data analysis part, there were around $15 \%$ who were able to present their data clearly but sadly, they could not make sense of the numbers they have obtained. It seems ironic because some of the students who were able to design a reliable experiment, certainly identified the data they needed in order to answer the question.

Evidently, the comments of the students give an impression that they lack integrated science process skills, such as interpreting data and drawing conclusions from it. Nevertheless, teachers must not expect great improvements in the learners' science process skills especially when they had limited exposure to higher level of inquiry and have been repeatedly performing 
confirmatory experiments. Abdulhanung, Supasorn and Samphao [15] remarked that inquiry is one of the most effective teaching approaches to enhance one's science process skills. Learners that were given, even a few, chances to improve their science process skills through inquiry become more self-confident, scientifically skillful, critical thinkers who are unafraid of doing science [16].

\subsection{Students' Anxiety Level}

The data from the Physics Laboratory Anxiety Assessment Scale (PLAAS) showed that the learners disagree with almost all of the items in the first strand regarding anxiety about finishing the experiment. Most of the learners reported that they felt no stress in answering questions related to the conclusion part of the experiment. In fact, they neither fear not being able to draw a conclusion from their gathered data nor being able to reach the correct conclusion. In the same way, majority of the students were not afraid whether their obtained data differ from their hypothesis statement. Furthermore, it is sad to note, that being late with the experiment do not cause any stress to them. The only anxiety they have expressed is in making a visual presentation for their data.

In the second strand - anxiety about doing the experiment as intended - the learners disagree with all four statements. Sadly, majority of the participants were not worried about not being able to understand the purpose of the experiment and whether they do the experiment properly or not. Not being able to determine the right materials for the experiment does not worry them as well. However, contrary to the learners' negative response on the statement, "I am worried about determining the material required for the experiment", they have expressed anxiety to the use of the materials in the laboratory. Most of them conveyed that they were uneasy when using laboratory equipment and installing experimental set-up. Commenting on graphs and charts was also difficult for them.

The last strand consisted of statements about constant anxiety towards the physics laboratory. The learners neither feel uneasy doing the physics experiments nor did they feel frightened when asked by the teacher. However, it is very sad to note that half of the respondents conveyed that they would not take Physics lessons if they have a choice. It is sad to know that the respondents do not seem to see the importance of conducting a scientific investigation and writing a laboratory report as seen in their responses in the PLAAS. During the interview, the students expressed enjoyment in doing experiments. However, they only like the part where they manipulate things and see the outcome. All other things that come along with it does not interest them, especially the idea of putting their minds to work and doing tasks beyond their comfort zones.

\subsection{Association of Laboratory Performance and Anxiety Level}

We know that Physics is often perceived as hard and difficult to understand; a glance at an equation is enough to scare students away. Berber [11] comments that physics laboratory receives an equal portion of negative attitudes as much as physics lessons and exams get, and this negative attitude is expressed as anxiety. In this study, the anxiety level of the Grade 8 students is reported at 3.07, which is intermediate. The correlation coefficient between Laboratory Performance and Anxiety Level was found to be -0.052 , which is not significant.

\subsection{Analysis of Reflective Journals and Interview}

This section presents the result of the interview with the five students who obtained the highest scores and the five students who obtained the lowest scores in the PLAAS. Aside from the interview, the journals of these students were also probed. The data was then transcribed, 
coded and categorized into themes. During the interview, the students were asked the following questions:

1. What part of the experiment did you enjoyed most?

2. What part of the experiment did you find difficult to do?

3. Were you able to finish your experiment? If no, what do you think is the primary reason of non-accomplishment?

4. How do you like Physics to be taught?

Analysis of the qualitative data led to identification of themes: (a) factors influencing student' performance on GIPE, (b) students' learning preferences and personality traits, (c) emotional reaction to outcome, and (d) students' perspective of guided inquiry Physics experiments.

The following factors are relevant to the students' laboratory performance: working as a team, supportive behavior, science process skills, use of language, time constraint, and readiness to high level of inquiry.

In a collaborative work, communication is vital. If learners contain their thoughts, feelings and circumstances to themselves, barriers to communication are set up [17]. One participant affirmed this by saying that they were able to come up with a good experimental procedure because they have listened to each other's idea. Another student mentioned that every member of their group felt responsible and commitment to accomplish the task.

Another factor that may influence the students' performance on guided inquiry Physics experiment is behavior. While the students conveyed that doing this type of inquiry activity is hard and they expressed that it is the most challenging experiment that they did so far, it is pleasing to note that despite all these, the students took the challenge positively. One student articulated, "...I enjoyed because we tried our best to get a good score. I think this activity is the hardest among all the lab activities that we have performed."

During the interview, one factor that contributed to the laboratory performance' low result was brought to light. It showed that the students lack the requisite integrated science process skills. The following excerpts from the interview support this:

"...I did not understand the problem"

"...I have measured the water temperature in the three beakers but I do not know how to explain the data I obtained, I don't know the implication of the values that I got"

"...I don't know what to write in the laboratory report"

"When I listen to my teacher on how it (hypothesis) is constructed, it seems easy but when time comes to do it by myself, it's hard. I find it difficult because I don't understand the problem, I can't point which variables should be involved."

"...I really don't understand the problem, it is confusing"

"I felt nervous because we may not do it right"

The lack of integrated science process skills among students were very much evident in their output. Through the interview, the teacher-researcher learned that the students were taught how to conduct a simple investigation during the first quarter of their Grade 7 science subject. Their task was to perform a simple guided inquiry experiment in Chemistry and to produce a laboratory report. However, after the submission of the manuscript, feedback from their teacher was lacking so they cannot figure out whether what they did was wrong or right. The students were also saying that this is the first time that they were given a high level of inquiry.

Language use was a consistent aspect that was raised by the students. Science is taught using the English language in the Philippines but many of the students do not speak English at home. During the interview, two of the learners expressed difficulty in articulating using the English language. "It's difficult to express my idea in English, if we're allowed to write in Filipino, 
maybe it will be a lot easier." Maerten-Rivera et al [18] noted in their study that English Language Arts (ELA) is a significant predictor for science achievement. The aspect of time constraint was also mentioned by the students. A participant expressed that it is hard to plan an experiment when the time is short.

The last factor that has been identified as contributor to laboratory performance is readiness. Readiness is a term used to describe preparation for a transition. "Making our own experiment is very hard, because we were used to follow as instructed in the laboratory worksheet..." This statement from a student clearly suggest that they are not so ready for a guided inquiry Physics experiment. They were accustomed to "cookbook type" type of experimentation, therefore, they needed more guidance and instruction until they reach a certain level of cognitive development required for this high level of inquiry. The teachers must provide intervention programs aimed to develop science process skills, raise learners' confidence and lower frustration levels while still maintaining a high level of intellectual.

\section{Conclusion}

Open-ended laboratory and authentic research seem to be a more appropriate way to facilitate students' development of higher-order inquiry skills [19]. In this light, a guided inquiry Physics laboratory experiment was employed to three (3) heterogeneous intact classes of a National Trade School. The purpose of this study was to provide a snapshot of the responses of Grade 8 students undergoing GIPE. The results revealed that the Grade- 8 respondents were not fully equipped for a GIPE. They have obtained below average success rates for the various parts of the laboratory report: problem, hypothesis, experiment to test the hypothesis, data analysis, interpretation, and conclusion. The following factors are relevant to the students' laboratory performance: working as a team, supportive behavior, science process skills, use of language, time constraint, and readiness to high level of inquiry.

The over-all anxiety level of the students in the Physics Laboratory Anxiety Assessment Scale is 3.07, which is rated as intermediate. There is no clear indication that the Physics laboratory performance and anxiety levels of the learners were interrelated.

Interview data revealed that learners wanted their physics course to be rich in experiments. They possess childlike traits who like to manipulate, explore, question, and discover things with adequate level of autonomy. However, they still prefer cookbook type of experimentation over guided inquiry Physics experiment though the former does not develop integrated science process skills among them. The learners perceive the GIPE as intellectually challenging, difficult, and frustrating but it provides experiential learning. Most of the learners do not like to engage on difficult tasks and write laboratory reports. Following instructions in the experiment sheet and answering simple questions eases them. Nevertheless, expressions of sense of achievement were documented when learners successfully finish the task while statements of disappointment were articulated when they failed.

This research study provided the stakeholders a snapshot of the scenario when high school students are given a high-level inquiry laboratory physics task. The data revealed that students experienced difficulty in proposing a sensible answer to the task. Consequently, stakeholders play an important role to develop a scheme leading to the adequate development of basic and integrative science process skills, independence and confidence necessary to complete a task of moderate difficulty among learners. Gradual deviation from participation in procedural lab 
activities and adjusting the levels of engagement of students are effective methods to raise students who depend on cook-book type of investigation to complete a slightly new task [19].

Several factors must be considered in designing laboratory programs in the schools so that when level of inquiry is increased, anxiety of learners will not follow. The key is conditioning. The learners must be conditioned to perform laboratory activities in progressing level of inquiry by constantly engaging them in a recurring sequence of learning instruction.

\section{References}

[1] SEI-DOST and UP NISMED 2011 Framework for Philippine Science Teacher Education (Manila: SEI-DOST \& UP NISMED)

[2] Ghatty S L 2013 Assessing students' learning outcomes, self-efficacy and attitudes toward the integration of virtual science laboratory in general physics Retrieved from http://0search.proquest.com.lib1000.dlsu.edu.ph/docview/ 1431981545?accountid=28547

[3] Chan A W 2004 The assessment of laboratory performance skills in grade 9 science via individuals and pairs Retrieved from http://0search.proquest.com.lib1000.dlsu.edu.ph/docview/305078239? accountid=28547

[4] Rovira-Figueroa N D L A 2009 Assessing the factors that affect the way(s) high school chemistry students write effective laboratory reports (Doctoral Dissertation, Purdue University).

[5] Hodson D 1998 Is this really what scientists do? Seeking a more authentic science in and beyond the school laboratory In Wellington, Practical work in school science: Which way now (London: Routledge) 93-108

[6] Hofstein A and Lunetta V N 2004 Sci. Educ. 88 28-54

[7] National Research Council 1996 National Science Eucation Standards (Washington, DC: National Academy Press)

[8] Alozie N M, Grueber D J, and Dereski M O 2012 Amer. Bio. Teach. 74 485-489

[9] Arslan A 2014 Proc.-Soc. and Beh. Sci. 141 407-412

[10] Etkina E, Van Heuvelen A, White-Brahmia S, Brookes D T, Gentile M, Murthy S and Warren A 2006 Phys. Rev. Spec. Top. - Phys. Educ. Res. 2(2) 020103

[11] Berber N C 2013 Asia-Pac. Forum Sci. Learn. and Teach. 14 1-18

[12] Towndrow P A, Ling T A \& Venthan A M 2008 Eurasia J. Math., Sci. \& Tech. Educ. 4 279-283

[13] Harlen W 2006 Assessment \& Inquiry-Based Science Education: Issues in Policy and Practice (Trieste: IAP)

[14] Miller T 2014 Inquiry-based Learning for Faculty and Institutional Development: A Conceptual and Practical Resource for Educators (Emerald Group Publishing Limited)

[15] Abdulhanung D, Supasorn, and Samphao A 2011 J. of Srinakharinwirot Univ. 3 54-62

[16] Deters K M 2005 J. Chem. Educ. 82 1178-1180

[17] Koh M H and Hill J R 2009 Int. J. E-Learn. \& Dist. Educ. 23 69-92

[18] Maerten-Rivera, J., Myers, N., Lee, O., \& Penfield, R. (2010). Student and School Predictors of Standardized Assessment in Science. Science Education, 94, 937- 962.

[19] Green N C, Edwards H, Wolodko B, Stewart C, Brooks M \& Littledyke R 2010 Dist. Educ. 31257 273. 